\title{
Commentary: Basic Research in HIV Vaccinology Is Hampered by Reductionist Thinking
}

\author{
Marc H. V. Van Regenmortel* \\ CNRS, School of Biotechnology, University of Strasbourg, Strasbourg, France
}

Keywords: HIV vaccines, reverse vaccinology, philosophy of science, bioethics of vaccine trials, reductionism

\section{A commentary on}

Basic Research in HIV Vaccinology Is Hampered by Reductionist Thinking by King MR. Front Immunol (2016) 7:42. doi: 10.3389/fimmu.2016.00042

Structure-based reverse vaccinology (RV) (1) attempts to develop an HIV-1 vaccine by determining the 3-D structure of complexes of HIV-1 Env epitopes bound to broadly neutralizing monoclonal antibodies (bnMabs) (2). For more than 10 years, hundreds of investigators have tried, without success, to transform Env epitopes of known structure into effective vaccine immunogens, because they thought that epitopes that bind to affinity-matured bnMabs would also be able to induce similar antibodies when used as immunogens (3).

Using the convergence argument (4), I suggested that all these independently obtained negative results justified the conclusion that RV was unlikely to lead to a successful vaccine because it is based on invalid reductionist thinking (5). King (6) disagreed with this conclusion because it was based on inductive reasoning (i.e., generalizing from a limited body of evidence), and there was therefore no "proof" that the conclusion was correct (7). Indeed, experimental science never leads to absolute certainty, since certainties are only achieved by logical, deductive reasoning and are not derived from empirical experimentation. When Einstein declared "It makes no sense to do the same thing over and over again and expect a different result," he did not contest that scientific conclusions are always reached by inductive inferences that may have only a reasonable probability of being correct.

My convergence argument that RV is inappropriate for developing an HIV vaccine, however, was only a back-up argument (5), since the actual reason why RV failed is that it did not have a sound theoretical basis corresponding to our current knowledge of immunological specificity and anti-HIV immune responses. For instance, RV does not take into account that the immune system is degenerate $(3,8)$ and that antibodies and paratopes are never monospecific for a single epitope but are always polyspecific (9) or even heterospecific (10) for a large number of epitopes. This means that a single antibody is always able to bind several epitopes, besides the one observed by X-ray crystallography of one paratope-epitope complex. Thus, there is no reason to believe that this epitope of known structure is necessarily the one that induced the antibody and could be expected to elicit bnAbs when used as vaccine immunogen.

Another theoretical misunderstanding by many proponents of RV is that they believe that when they improve the antigenic reactivity of one Env epitope with respect to a single bnMab, using molecular engineering, this amounts to "designing" a superior vaccine immunogen capable of eliciting protective antibodies (11). In so doing, they confuse antigenicity, which is a chemical property that allows a molecule to bind to an antibody, with immunogenicity, which is a biological property involving an appropriate immune system. This is typical of reductionist thinking, which assumes that biology can be reduced to chemistry and that an antigen is necessarily able to elicit the antibodies that it can react with. In fact, many factors that determine which antibodies will be produced are external 
to epitope-paratope recognition and originate in the immunized host. RV is also ineffective in the case of HIV, because neutralizing anti-HIV Abs are only obtained after a lengthy process of Ab affinity maturation, which is usually not the case for immune responses to other viruses. As a result, RV is not applicable to the epitopes of known structure that are recognized only by affinity-matured antibodies. Current attempts to develop vaccine immunogens from Env epitopes that do not bind germline B cell receptors or maturation intermediates present in naive individuals actually depart from the original RV strategy, which does not require the unraveling of antibody maturation pathways (11).

Another reductionist limitation of RV is that it makes use only of epitopes recognized by a limited number of bnMabs, thereby neglecting the fact that the entire surface of a protein contains a very large number of overlapping epitopes and potentially immunogenic regions (12). However, it is well-known that effective vaccine-induced antibody responses are always polyclonal and recognize a wide variety of epitopes (13).

King (6) also pointed out that HIV vaccine development and related efficacy trials in humans present numerous ethical constraints that are particularly challenging. He suggested that it may be unethical to pursue attempts to develop an HIV-1 vaccine by $\mathrm{RV}$, if scarce resources could be used more effectively to combat the AIDS epidemic and its huge societal problems by other means. Such a conclusion is reinforced by the theoretical shortcomings of

\section{REFERENCES}

1. Van Regenmortel MHV. Two meanings of reverse vaccinology and the empirical nature of vaccine science. Vaccine (2011) 29:7875. doi:10.1016/j. vaccine.2011.08.063

2. Burton DR. Antibodies, viruses and vaccines. Nat Rev Immunol (2002) 2:706-13. doi:10.1038/nri891

3. Van Regenmortel MHV. Requirements for empirical immunogenicity trials, rather than structure-based design, for developing an effective HIV vaccine. Arch Virol (2012) 157:1-20. doi:10.1007/s00705-011-1145-2

4. Klee R. Introduction to the Philosophy of Science. Oxford: University Press (1997). p. 212-8.

5. Van Regenmortel MHV. Basic research in HIV vaccinology is hampered by reductionist thinking. Front Immunol (2012) 3:194. doi:10.3389/fimmu. 2012.00194

6. King MR. Commentary: basic research in HIV vaccinology is hampered by reductionist thinking. Front Immunol (2016) 7:42. doi:10.3389/fimmu. 2016.00042

7. Chalmers AF. What is this Thing Called Science? 3rd ed. Oxford: University Press (1999).

8. Wucherpfennig KW, Allen PM, Celada F, Cohen IR, De Boer R, Garcia KC, et al. Polyspecificity of T cell and B cell receptor recognition. Semin Immunol (2007) 19:216-24. doi:10.1016/j.smim.2007.02.012

9. Eisen HN, Chakraborty AK. Evolving concepts of specificity in immune reactions. Proc Natl Acad Sci U S A (2010) 107:22373-80. doi:10.1073/ pnas. 1012051108

10. Van Regenmortel MHV. Specificity, polyspecificity, and heterospecificity of antibody-antigen recognition. J Mol Recognit (2014) 27:627-39. doi:10.1002/ jmr.2394

11. Van Regenmortel MHV. Why does the molecular structure of broadly neutralizing monoclonal antibodies isolated from individuals infected with HIV-1 not inform the rational design of an HIV-1 vaccine? AIMS Pub Health (2015) 2:183-93. doi:10.3934/publichealth.2015.2.183

12. Sela-Culang I, Kunik V, Ofran Y. The structural basis of antibody-antigen recognition. Front Immunol (2013) 4:302. doi:10.3389/fimmu.2013.00302
RV outlined above, which suggest that other vaccine approaches should rather be investigated and funded (14).

It could also be argued that the unwillingness of regulatory authorities to allow small-scale human vaccine trials, unless positive results have been obtained earlier with non-human primates (NHPs), may also be ethically questionable. It is widely accepted today that a vaccine response in NHPs (whether positive or negative) is not at all predictive of what is likely to happen in humans $(15,16)$. For instance, this means that a vaccine that shows no efficacy in NHPs may never be tested in humans, and thus that its possible efficacy would not be discovered because of ethical considerations. For instance, it is obvious today that the thalidomide disaster could not have been avoided if pregnant NHPs had first been tested in toxicity trials, since the drug is only teratogenic in humans (17). It should in fact be accepted that the only reliable model system for a human vaccine are human subjects (18, 19). Small-scale human trials $(20,21)$, using, for instance, HIVinfected individuals with temporarily interrupted ART, may be one approach that could be used to evaluate potential therapeutic HIV vaccines.

\section{AUTHOR CONTRIBUTION}

The author confirms being the sole contributor of this work and approved it for publication.

13. Mascola JR, Haynes BF. HIV-1 neutralizing antibodies: understanding nature's pathways. Immunol Rev (2013) 254:225-44. doi:10.1111/imr.12075

14. Van Regenmortel MHV, Andrieu JM, Dimitrov DS, Ensoli B, Hioe CE, Moog C, et al. Paradigm changes and the future of HIV vaccine research: a summary of a workshop held in Baltimore on 20 November 2013. J AIDS Clin Res (2014) 5:281. doi:10.4172/2155-6113.1000281

15. Shedlock DJ, Silvestri G, Weiner DB. Monkeying around with HIV vaccines: using rhesus macaques to define 'gatekeepers' for clinical trials. Nat Rev Immunol (2009) 9:717-28. doi:10.1038/nri2636

16. Shanks N, Greek R, Greek J. Are animal models predictive for humans? Philos Ethics Humanit Med (2009) 4:2. doi:10.1186/1747-5341-4-2

17. Greek R, Shanks N, Rice MJ. The history and implications of testing thalidomide in animals. J Philos Sci Law (2011) 10:1-32. doi:10.5840/jpsl20111133

18. Horrobin DF. Modern biomedical research: an internally consistent universe with little contact with medical reality? Nat Rev Drug Discov (2003) 2:151-4. doi:10.1038/nrd1012

19. Van Regenmortel MHV. Reductionism and complexity in molecular biology. EMBO Rep (2004) 5:1016-20. doi:10.1038/sj.embor.7400284

20. Gandhi RT, O’Neill D, Bosch RJ, Chan ES, Bucy RP, Shopis J, et al. A randomized therapeutic vaccine trial of canarypox-HIV-pulsed dendritic cells vs. canarypox-HIV alone in HIV-1-infected patients on antiretroviral therapy. Vaccine (2009) 27:6088-94. doi:10.1016/j.vaccine.2009.05.016

21. Palma P, Gudmundsdotter L, Finocchi A, Eriksson LE, Mora N, Santilli V, et al. Immunotherapy with an HIV-DNA vaccine in children and adults. Vaccines (2014) 2:563-80. doi:10.3390/vaccines2030563

Conflict of Interest Statement: The author declares that the research was conducted in the absence of any commercial or financial relationships that could be construed as a potential conflict of interest.

Copyright (c) 2016 Van Regenmortel. This is an open-access article distributed under the terms of the Creative Commons Attribution License (CC BY). The use, distribution or reproduction in other forums is permitted, provided the original author(s) or licensor are credited and that the original publication in this journal is cited, in accordance with accepted academic practice. No use, distribution or reproduction is permitted which does not comply with these terms. 